Original paper

\title{
Increasing Resilience through Interaction: Stakeholder Workshop on Aviation and Volcanic Ash
}

\author{
Uta Reichardt ${ }^{1}$, Gudmundur F. Ulfarsson ${ }^{2}$, Gudrun Pétursdóttir ${ }^{3}$
}

Received: 04/12/2017 / Accepted: 21/11/2018 / Published online: 06/13/2019

\begin{abstract}
The Eyjafjallajökull volcanic eruption in 2010 illustrated the threat that Icelandic volcanoes can pose to global air transportation and the connected economy. It highlighted the necessity for crisis management and contingency planning that crosses borders. This research obtained insights into how the European aviation volcanic risk management has progressed since 2010. It developed extreme volcanic scenarios to investigate the robustness of the aviation sector and to identify improved mitigation measures.

This paper describes a multi-level methodology to build a lasting relationship with, and between, stakeholders and to obtain relevant data. The first step consisted of establishing a face-to-face interaction with stakeholder representatives on an individual basis. Subsequently the group was invited to a one-day participatory stakeholder workshop where extreme volcanic events and their effects on aviation were investigated using scenario narratives.

The workshop's set-up proved successful in enabling discussions and obtaining information. The stakeholders' positive responses to the invitation, as well as their feedback after the workshop, illustrate their interest in this type of workshop. The feedback showed that the stakeholders appreciated the opportunity to meet and specifically to discuss aviation contingency issues. The workshop raised awareness and facilitated information flow between the stakeholders.

The paper describes this case, provides generalized guidance on how to build fruitful interaction between interviewees in a study, sheds light on the resulting impact, and presents opportunities to create value beyond the study.
\end{abstract}

Key words Stakeholder engagement; Risk management; Aviation; Volcanic eruption; Participatory workshop.

1 Environmental and Natural Resources Program, University of Iceland, Sæmundargata 2, 101 Reykjavik, Iceland.

2 Faculty of Civil and Environmental Engineering, University of Iceland, Hjardarhagi 2-6, 107 Reykjavik, Iceland

3 Institute for Sustainability Studies, University of Iceland, Sæmundargata 2, 101 Reykjavik, Iceland 


\section{INTRODUCTION}

There are 32 volcanic systems in Iceland that are considered active (Gudmundsson 1987; IMO 2014). Historic records (see Gudmundsson 1987; Haraldsson 2012; Höskuldsson et al. 2013) suggest a volcanic eruption in Iceland approximately once every five years. Recent studies point to the possibility of increased eruption frequency due to less pressure from melting glaciers (Pearce 2012; Schmidt et al. 2013; Compton et al. 2015), posing a greater threat to the local population. The particles in volcanic ash vary in size and weight. Volcanic ash can, if light enough, be lifted to great elevations in the atmosphere and can remain there for significant amounts of time.

A number of historic volcanic eruptions in Iceland have had an impact beyond the island's borders. A widely known example is the emission of ash and gases in the Lakagígar eruption in 1783-1784, which is speculated to have led to weather changes that subsequently impaired harvests in Western Europe and is thus considered to have possibly contributed to triggering the French Revolution (Wood 1992). Again, the potency of Iceland's volcanism aroused global attention in spring 2010, when Eyjafjallajökull erupted with severe consequences for aviation (Ulfarsson and Unger 2011). Depending on the density of the ash surrounding a flying jet aircraft, the threat to the jet engines ranges from shortening their lifetime to complete failure (Dunn and Wade 1991; Guffanti and Miller 2002). The eruption of the Eyjafjallajökull volcano in April 2010 (hereafter abbreviated as E2010) was modest in comparison with the magnitude of other eruptions (Gudmundsson et al. 2012), yet unprecedented in the impact it had on global aviation and the economy. E2010 prevented millions of passengers, as well as goods, from reaching their destination, as air traffic was halted in Europe for several days (Ulfarsson and Unger 2011). It led to what is known to be the greatest disruption of air traffic since World War II and caused an estimated worldwide loss of 5 billion USD with more than 100,000 flights cancelled (OxfordEconomics 2010).

The event illustrated the vulnerability of the increasing interconnectedness of global infrastructure and the lack of coordination between institutions at the time. It highlighted the necessity for crisis management and contingency planning that crosses borders, both on a physical and institutional level (Alexander 2013).

As part of the EU project ENHANCE on stakeholder partnerships, this study obtained insights into how the European aviation sector's risk management regarding volcanic ash has progressed since E2010. This research focused on cooperation and information exchange between Icelandic and other European stakeholders. It aspired to enable interaction and enhanced discussion between the stakeholders. Expert interviews were conducted using the method of scenario narratives and visualization in a stakeholder workshop to facilitate the discussion and for the stakeholders to jointly develop improvement measures.

This paper describes the multi-level method the research study used to build a relationship with the stakeholders and gain a deeper understanding, both at an individual level and through group dynamics. The purpose of the paper is to share the study's methodology with a focus on 
the stakeholder workshop as a practical example when working with stakeholders from diverse institutions and backgrounds. The article stresses the importance of providing a physical opportunity for stakeholders to meet and discuss scenario ideas for the risk management of transboundary and multi-spectral hazards. The paper proposes a combination of methods to be used as a guidance by other researchers when conducting a stakeholder analysis with the use of scenarios. It is specifically valuable to those engaged in the field of volcanic ash and international aviation but can be applied to different contexts and hazards.

Following the introduction, the second section of the paper gives a brief schematic overview of the institutions represented in the case study and their roles in the management of volcanic ash. The third section provides an overview of the methods that were used in obtaining the data. This is followed by a description of the composition and process of the stakeholder workshop in detail. It is followed by the stakeholders' feedback, which was collected throughout the course of the study. Finally, there are concluding remarks and recommendations.

\section{STAKEHOLDER OVERVIEW}

A volcanic eruption calls for various stakeholders to form an alliance and cooperate on different levels to mitigate the adverse impacts of this natural hazard on people, infrastructure, and machines. Bearing the importance of each of them in mind, the study focuses on the stakeholders that exist around the aviation response while leaving out primarily land-based response actors, e.g. direct on-the-ground emergency management.

According to their position in the process, the stakeholders can be grouped into information providers, crisis coordination and network management, air navigation service providers, global/international and national regulators, and aircraft operators. An overview of the sectors, roles, and associated institutions can be found in Table 1.

Global and national regulators provide the legal framework for aircraft operations. In case of a volcanic eruption, the information providers collect information on the eruption and create forecast maps of predicted ash concentrations. These maps facilitate the decision-making process of the aircraft operators on whether to proceed, divert or cancel flights. Air navigation service providers coordinate the air traffic. To ensure a smooth transition of flight plans, the network manager facilitates on a European level and acts as crisis coordinator if needed.

Since the European airspace is a composition of multiple national and international airspaces, the disruption of air traffic due to E2010 was managed and coordinated both on national and international levels. The effective decision-makers were mainly at the national level, following regulations, contingency plans, and recommendations from international and global regulatory bodies while using information provided by national and international institutions. 
Table 1. Overview of sectors, roles, and institutions

\begin{tabular}{|c|c|c|}
\hline Sector & Role in volcanic ash management & Institutions \\
\hline Global air regulator & $\begin{array}{l}\text { Development of global standards and } \\
\text { recommended practices }\end{array}$ & $\begin{array}{c}\text { ICAO (International Civil Aviation } \\
\text { Organization) }\end{array}$ \\
\hline International regulator & $\begin{array}{c}\text { Limit-setting for shared air transportation } \\
\text { zones }\end{array}$ & $\begin{array}{c}\text { EU Directorate General for Mobility } \\
\text { and Transport }\end{array}$ \\
\hline International facilitator & $\begin{array}{c}\text { Representative of airline industry, } \\
\text { formulates industry policy on critical } \\
\text { aviation issues }\end{array}$ & $\begin{array}{l}\text { IATA (International Air Transport } \\
\text { Association) }\end{array}$ \\
\hline National regulator & $\begin{array}{l}\text { Responsible for the state's Volcanic Ash } \\
\text { Contingency Plan, approval of Safety Risk } \\
\text { Assessment procedures, airspace closure }\end{array}$ & $\begin{array}{l}\text { ICETRA (Icelandic Transport } \\
\text { Authority) }\end{array}$ \\
\hline National regulator & $\begin{array}{l}\text { Supervision of ISAVIA and ICETRA, } \\
\text { resource allocation to fund extra costs, } \\
\text { policies regarding risk management (e.g., } \\
\text { transportation plans) }\end{array}$ & Icelandic Ministry of the Interior \\
\hline $\begin{array}{l}\text { Crisis coordination and } \\
\text { network management }\end{array}$ & $\begin{array}{l}\text { Network management and crisis- } \\
\text { coordination response }\end{array}$ & $\begin{array}{l}\text { EUROCONTROL (European } \\
\text { Organisation for the Safety of Air } \\
\text { Navigation) }\end{array}$ \\
\hline Information provider & $\begin{array}{l}\text { Issue weather observations and } \\
\text { forecasting. Monitoring of volcanic } \\
\text { eruption, detection of seismic activity, ash } \\
\text { measurements, issue warnings }\end{array}$ & $\begin{array}{l}\text { IMO (Icelandic Meteorological } \\
\text { Office) }\end{array}$ \\
\hline Information provider & $\begin{array}{l}\text { Forecasts expected location of the } \\
\text { volcanic ash cloud, issued as VAG and VAA }\end{array}$ & $\begin{array}{l}\text { London VAAC (Volcanic Ash } \\
\text { Advisory Centre) }\end{array}$ \\
\hline Information provider & $\begin{array}{l}\text { Engine manufacturer, guidance on engines } \\
\text { for airlines and information for national } \\
\text { governments, European Aviation Safety } \\
\text { Agency }\end{array}$ & Rolls-Royce \\
\hline $\begin{array}{l}\text { Air navigation service } \\
\text { provider }\end{array}$ & $\begin{array}{c}\text { Management of airport operations and air } \\
\text { traffic in control area }\end{array}$ & $\begin{array}{l}\text { ISAVIA (Icelandic Air Traffic } \\
\text { Management) }\end{array}$ \\
\hline Aircraft operators & $\begin{array}{c}\text { Air transportation and service providers to } \\
\text { passengers and cargo }\end{array}$ & $\begin{array}{l}\text { Icelandair (Icelandic aircraft } \\
\text { operator) }\end{array}$ \\
\hline
\end{tabular}

(Based on: Reichardt et al. 2015)

To trace briefly the response being studied, as it happened during E2010, the Icelandic Meteorological Office (IMO) initially informed the London Volcanic Ash Advisory Centre (VAAC) and the Central Flow Management Unit of EUROCONTROL about the new eruption and the emerging ash plume of E2010. The VAAC issued Volcanic Ash Graphics (VAGs) and Volcanic Ash Advisories (VAAs). Based on the forecasted distribution maps and following the recommendations of the International Civil Aviation Organization (ICAO) contingency plan to avoid ash-contaminated airspace (ICAO 2009), as well as the EU recommendations of ash density limits, EUROCONTROL recommended closure of the airspace predicted to be contaminated based on the VAAC forecast. This closure recommendation was submitted to the various air navigation 
service providers operating under national civil aviation administration oversight, who initiated the closures in their respective airspaces. Questioning the rationale behind the regulationspecified ash-density limits and in light of increasing economic losses, EUROCONTROL, national civil aviation administrations, and aircraft operators called for a coordinated European approach and review of the existing guidelines. The European Commission's Directorate General for Mobility and Transport, with the agreement of the national ministries of transport, reviewed the guidelines on the limits of ash density and developed changes to EU regulations, which changed the no-flight zone and partially reopened airspace.

The study recognizes the limitations that come with the choice of stakeholders. The aviation industry is a broad field with stakeholders on the national, international and global level. A comprehensive study of all stakeholders involved goes beyond the temporal and financial limitations of this project. The research group thus worked with the main global and European stakeholders. On the national level, the project's focus was on Icelandic institutions due to project relevance and access. While this case was successfully analysed, the analysis does not comprehensively represent all stakeholders, since several remain outside this research.

\section{METHOD OVERVIEW}

The study investigates human interaction, collaboration, partnership and communication of stakeholders. The stakeholder groups' opinions and assessments thus formed the core part of the research outcome. For this, the aim was to build trust and a close relationship with the stakeholders. The process was divided into two sets of data-gathering cycles: Individual meetings with the stakeholders and the participatory stakeholder workshop with the stakeholders together in a group.

After the initial literature and policy review, the study developed a multi-level method for repeated interaction with the stakeholders. The emphasis was placed on meeting the stakeholders face-to-face in the first place to lay grounds for a lasting interaction. This proved to be a successful approach as all stakeholders were open for further discussion and information exchange through email, phone, and online meetings. In this section, the different steps are briefly described. The stakeholder workshop is described in the subsequent section.

\subsection{Preliminary Discussions}

In the beginning of the research, face-to-face meetings were conducted at a national level. The study group consulted experts of potential stakeholders such as the Civil Aviation Authority in Iceland, IMO, the Earth Science Institute at the University of Iceland, and ISAVIA to gather information about the field of study. A member of the research group facilitated as a note taker. The discussions helped to establish a general idea of the problem, the process, and potential 
stakeholders in question. The interview partners were asked to suggest institutions and contacts that they considered to be of value to the project.

\subsection{Face-to-Face Interviews}

Once the stakeholder group was identified, individual interviews were conducted with representatives and field experts from the London VAAC, EUROCONTROL, ICAO, ISAVIA, Icelandair, the University of Geneva, the University of Iceland, Reykjavik University, and RollsRoyce. They were asked about their experience, the decision-making processes at the time, and the impact E2010 had on them and their organizations. These were set up as face-to-face interviews, with guideline questionnaires, at the site of the institution and lasted between 70 minutes and 3 hours. Visiting the institution facilitated understanding of the process and was often combined with meeting further representatives who provided valuable insights to the research. All interviews were held in English, recorded and transcribed verbatim. They were partly complemented through additional communication with the interviewees via email and phone. The interviews further facilitated the trustful relationship between the researchers and the stakeholder. This greatly helped all further information requests and exchange and supported the successful turnout of the workshop.

\subsection{Participation in Internal Stakeholder Meetings}

Having established a personal relationship with the stakeholders through frequent interaction and the face-to-face interviews, the study group was allowed to participate as observers in internal stakeholder group meetings, such as the Volcanic Ash Exercise (VOLCEX) planning meeting, exercise and debrief meetings, as well as best practice VAAC workshops and other ICAO meetings. This not only strengthened the connection with established contacts but also provided access to other representatives from the aviation sector. It facilitated the gain of more information toward a comprehensive understanding of the whole process.

\subsection{Scenario Development}

The researchers developed two scenarios that exceeded E2010 in a) duration and b) magnitude, in order to facilitate the discussion with the stakeholders about the current procedures and what is needed to improve preparedness for more extreme cases than E2010.

The first scenario describes a new Eyjafjallajökull eruption of medium ash concentration in recurring eruptions over the course of 24 weeks (about four times longer than E2010). This long duration scenario helped the researchers collect information on the stakeholders' decisionmaking when facing a long period of continuous risk assessment and maintenance. The second scenario is based on the historic eruption of the Öræfajökull volcano in 1362 with a large ash emission within a rather short period of time (2-3 weeks). This scenario helped to capture the reaction of the stakeholders to a large-scale severe interruption of air traffic. Both scenarios are 
modelled under the meteorological conditions that were prevailing during E2010, with predominantly N-NW winds (Petersen 2010), which are especially unfavourable with respect to the European airspace. Although the uncertainties are considered too numerous to perform a detailed economic risk assessment, the financial consequences in both scenarios are expected to be in the order of billions of Euros. The scenarios are described in detail in Reichardt et al. (2018a).

The parameters of the volcanic eruptions were developed based on discussions with expert volcanologists from the FutureVolc research group at the University of Iceland. To model the extreme-case scenarios, the research group was in close cooperation with the Atmospheric Dispersion and Air Quality (ADAQ) Group at the UK Met Office which provided the NAME model as well as a training course and staff hours to facilitate the model set-up. The interaction included face-to-face and online meetings as well as email exchange.

\section{STAKEHOLDER WORKSHOP}

\subsection{Workshop Preparation}

The aim of the workshop was to get the experts' opinion on how to improve cooperation to manage the risk of volcanic ash. Therefore, the workshop was designed to require as little mediation or steering by the researchers as possible. It was intended to serve as a platform for stakeholders to talk and interact, steered only to make sure that every party was being heard and to help move the discussion further.

The majority of the stakeholders had been contacted and interviewed face-to-face in an earlier stage of the project, which helped establish personal relations which resulted in the exchange of first-hand information. This helped the preparation for the workshop. Since the workshop also served the purpose of further connecting the other European stakeholders with the Icelandic representatives, these institutions were addressed first and their availability on the suggested date confirmed.

Invitations sent by email or telephone were positive received by the stakeholders. The fact that international stakeholders intended to attend proved attractive. The word spread to a broader audience than initially targeted, which led to requests to be allowed to join the workshop.

The workshop was hosted by the research group and the participants were reimbursed for transportation and accommodation costs, where applicable.

Prior to the workshop, the stakeholders received a questionnaire regarding their institutions' procedures in case of volcanic eruptions and their experience during E2010. Thus some additional, comparable information could be collected and it was ensured that representatives at the workshop were up-to-date in their role and ready to discuss on the spot even if they had not been in this position during the E2010 event. 
The workshop design was inspired by the scenario workshop tool-kit developed under the EC project TRAMS: Training and Mentoring of Science Shops (Gnaiger and Schroffenegger 2008). The TRAMS document was especially helpful in assembling and bridging the separate parts of the workshop and defining the scenario run.

The workshop day was set up as an alternation between short presentations from research team mediators and the stakeholders, plenum discussions, scenario group discussions, and opportunities for the participants to discuss in smaller groups.

While the general process was discussed in plenum, the subgroup setting for the scenario runs allowed more in-depth discussions. A number of focus points, aspects and questions were developed as orientation for discussion in all the sessions. The discussion topics were supported by visualization tasks and intermittent change of locations to open up communication dynamics through changing positions and discussion partners. To ensure that the participants were aware of the research team's focus areas and questions, these were emphasized using printouts and flip charts. Furthermore, a colour code of differently coloured Post-it note blocks was applied to structure the outcome of the individual tasks for further analysis.

Breaks were an important issue to be considered during the set-up of the workshop agenda. The day started with a welcome coffee to provide an environment for casual interaction between the participants. In addition to lunch and coffee breaks, different locations within the building were used for different sessions to ensure motion and diversions during the day. This was also meant to give the participants an added opportunity to engage with each other.

The researchers had developed a detailed agenda, which listed the content, aim and tools needed for every part of the meeting. This helped establish a clear focus for each part of the workshop, ensured that all points were covered, and kept track of the timing of the workshop. For every subsection, one of the two researchers was appointed as a speaker to facilitate the preparation for the different parts of the workshop. The researcher who was not mediating kept track of the time and helped to facilitate, e.g., in discussion rounds. Two assistants helped the mediators capture the process of the workshop by taking notes, later used to develop the meeting minutes.

\subsection{Lift transfer Barriers (B) via contextualization}

The workshop was attended by eleven stakeholder representatives. One from EUROCONTROL, one from IATA, three from Icelandair, one from ICETRA, two from ISAVIA, one from the IMO, one from the Icelandic Ministry of the Interior, and one from Rolls-Royce. Table 2 presents the agenda of the stakeholder workshop. 
Table 2. Agenda of the stakeholder workshop

\begin{tabular}{|l|c|c|}
\hline Time & Activity & Location \\
\hline 08.45 & Welcome coffee & Room A \\
\hline 09.00 & Introduction to the project & Room A \\
\hline 09.30 & Stakeholder introductions & Room A \\
\hline 10.00 & Coffee break & Common area \\
\hline 10.15 & General process discussion & Room B \\
\hline 11.05 & Scenario run in groups & Room C and D \\
\hline 12.30 & Lunch & Cafeteria \\
\hline 13.30 & Scenario presentations and evaluation & Room B \\
\hline 14.20 & Discussion on implication for resilience & Room B \\
\hline 14.50 & Voting for obstacles and mitigation measures & Room B \\
\hline 15.10 & Wrap up & Room B \\
\hline 15.45 & Break & Restaurant \\
\hline 19.30 & Dinner and discussion of results and recommendations \\
\hline
\end{tabular}

After a brief welcome and introduction round, the aim of the first task was to create a common idea about the processes and connections between the institutions, as well as to collect first insights about potential improvements to current processes. This also facilitated an open discussion environment, making the participants comfortable to speak. Figure 1 demonstrates the outcome of the first task pinned to a whiteboard. The participants were handed a sheet of paper with their institution's name and asked to pinpoint their institution's main tasks and visualize the stakeholders' connections (drawn arrows) between each other in the general response to a volcanic eruption. Then the participants were asked to write down potential obstacles that could prevent the process from running efficiently (orange Post-its). At the end of this first part, a representative from each institution presented their position in the process and possible obstacles. Time was included for open discussion. This exercise also served to openly illustrate the stakeholders' position in the process. Further, this created a first discussion environment in preparation for the discussion in the scenario run. 


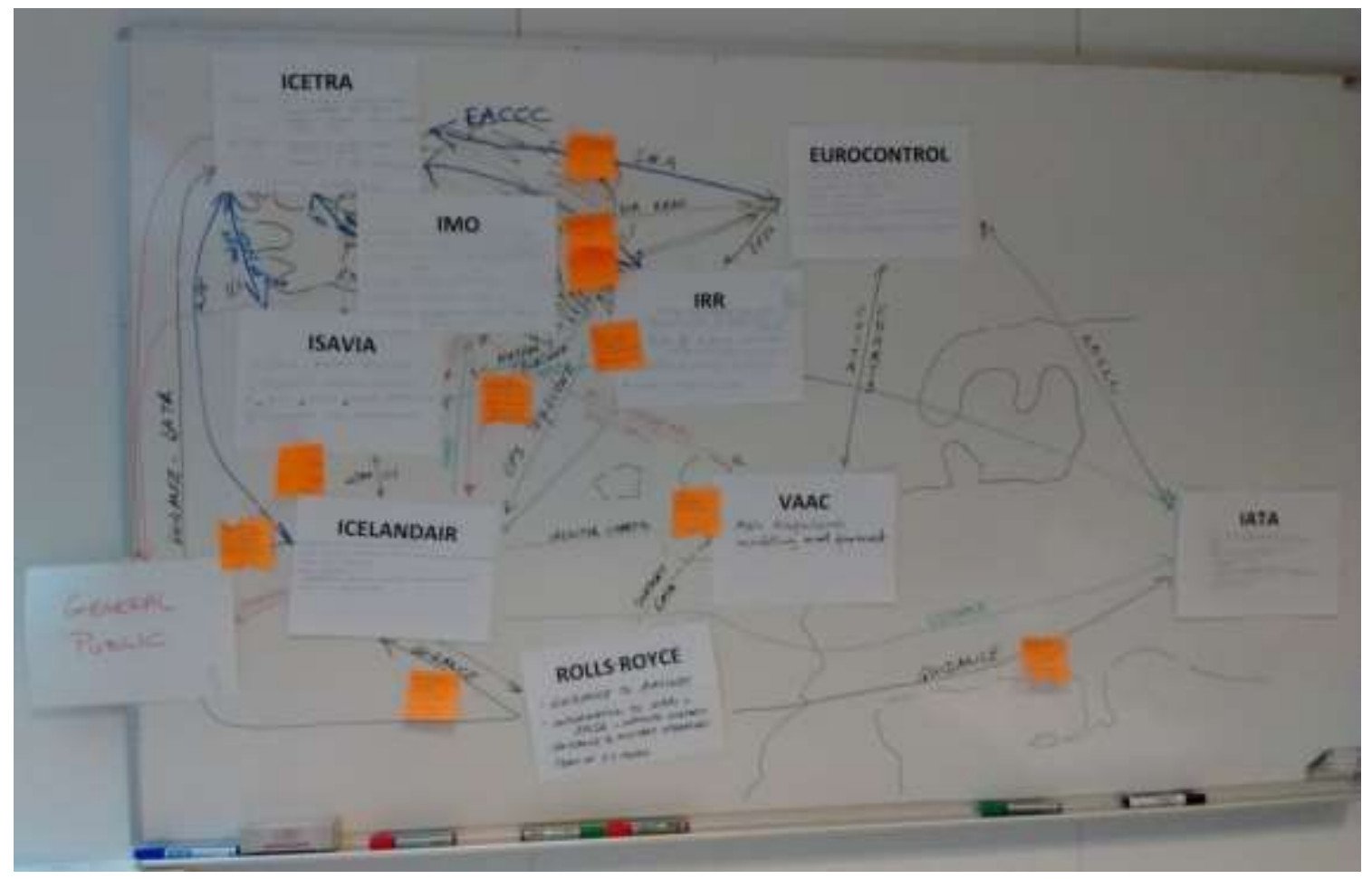

Figure 1. Stakeholder workshop, Task 1 outcome: Stakeholder main tasks and connections

(Source: Reichardt et al. 2015)

The second part of the workshop contained the scenario run. The stakeholders were divided into two groups and were presented with one scenario each. The information about the scenarios was presented in the form of artificial newspaper articles, graphically designed to be realistic in order to create a feeling of a real-life situation.

Group 1 (with representatives from IATA, IMO, ISAVIA, Icelandair and Rolls-Royce) was presented with the scenario of a long-lasting eruption with low concentrations of ash in the atmosphere over several months, which was introduced with the following narrative:

"50 shades of grey [Title]

Iceland's Eyjafjallajokull volcano continues to emit ash into the European Airspace for the 4th month in a row - air traffic industry on continuous alert. With almost constant ash concentration levels between $500-3000 \mu \mathrm{g} / \mathrm{m}^{3}$ in areas ranging from the Northern parts of Scotland to the Western tip of the Black sea in Europe's airspace, the Eyjafjallajokull volcano has kept the air traffic industry on its toes since late February. The initial eruption at the start of this year had a remarkable column height of $10 \mathrm{~km}$ and total erupted tephra volume of $1 \mathrm{~km}^{3}$. Subsequently new craters opened up beneath the Eyjafjalla glacier emitting ash columns of similar height and volume repeatedly. The new eruption yesterday was the 4th one within four months. 
Iceland's meteorological office said a change of wind direction in the past few days had sent the ash cloud again south and south-east towards Europe. Furthermore, uncommonly dry weather makes it likely for the ash to remain in the atmosphere for a few more days. "Eyjafjallajokull's warning shot in 2010 brought attention to the vulnerability of the European air traffic to the force of Icelandic volcanoes" the spokesman from Rolls-Royce, a major manufacturer of jet engines. "With the summer holidays starting all over Europe soon and no end of the eruption in sight, the continuous presence of ash ... [Continue reading]"

Group 2 (with representatives from EUROCONTROL, Icelandair, ICETRA, ISAVIA, and the Ministry of the Interior) discussed a scenario of an intense eruption with high concentrations of ash over the course of 2-3 weeks, presented in the following narrative:

\section{“Ashpocalypse now [Title]}

Iceland's Oræfajokull volcano outdoes its own historic performance from 1362 and covers the European airspace in ash - a doom for the air traffic industry?

"Eyjafjallajokull's warning shot in 2010 brought attention to the vulnerability of the European air traffic to Icelandic volcanoes and led to significant changes across the industry to increase resilience" says the spokesman from EUROCONTROL, the European Organization for the Safety of Air Navigation. "Yet, the Öræfajökull eruption from five days ago is on an entirely different scale." With a column height of $35 \mathrm{~km}$ and a total erupted volume of more than $10 \mathrm{~km}^{3}$, Iceland's tallest volcano exceeded its own historic magnitude from 1362. Back then, most of the emitted ash was transported North, Northwest from the volcano and thus threatened the Icelandic population, flora and fauna. This time, however, North-Northwesterly winds carry large amounts of ash straight into Europe's airspace. From the Northern parts of Scotland to the Western tip of the Black sea, ash concentration levels are still far above $4000 \mathrm{\mu g} / \mathrm{m}^{3}$, the threshold declared as high ash contamination. Uncommonly dry weather makes it likely for the ash to remain in the atmosphere throughout the week. EUROCONTROL's spokesman continues "This time, we ... [Continue reading]"

The mediators left the room during the group work to minimize the researchers' influence on the discussions. In order to follow the build-up of ideas, separate minute takers captured the process of the discussions. A number of focus questions were prepared on a flip chart beforehand to provide the groups with some guidance during the discussions. Focus areas were printed out and distributed on the group tables to keep the diverse topics in the stakeholders' view during the discussion. They were encouraged to add further areas that they considered important. The groups were asked to discuss how the scenario in question would affect the stakeholders and what obstacles (Figure 2, red Post-its) would be expected. 
Following this, the stakeholders were directed to discuss possible solutions (Figure 2, yellow Post-its) to the expected obstacles. In the following plenum session, the groups moved together to one room. Both groups presented their results to all workshop participants and the floor was opened to further discussion.

In the last part of the workshop, the participants were asked to vote for what they considered the most important obstacles/solutions. For this exercise, 6 sticky dots were handed out to every institution present, with up to three dots to vote for the most important obstacle to manage and up to three dots for the most important solution (Figure 2). For the voting, the stakeholders were encouraged to interact with each other and discuss their reasoning before making their final choices.

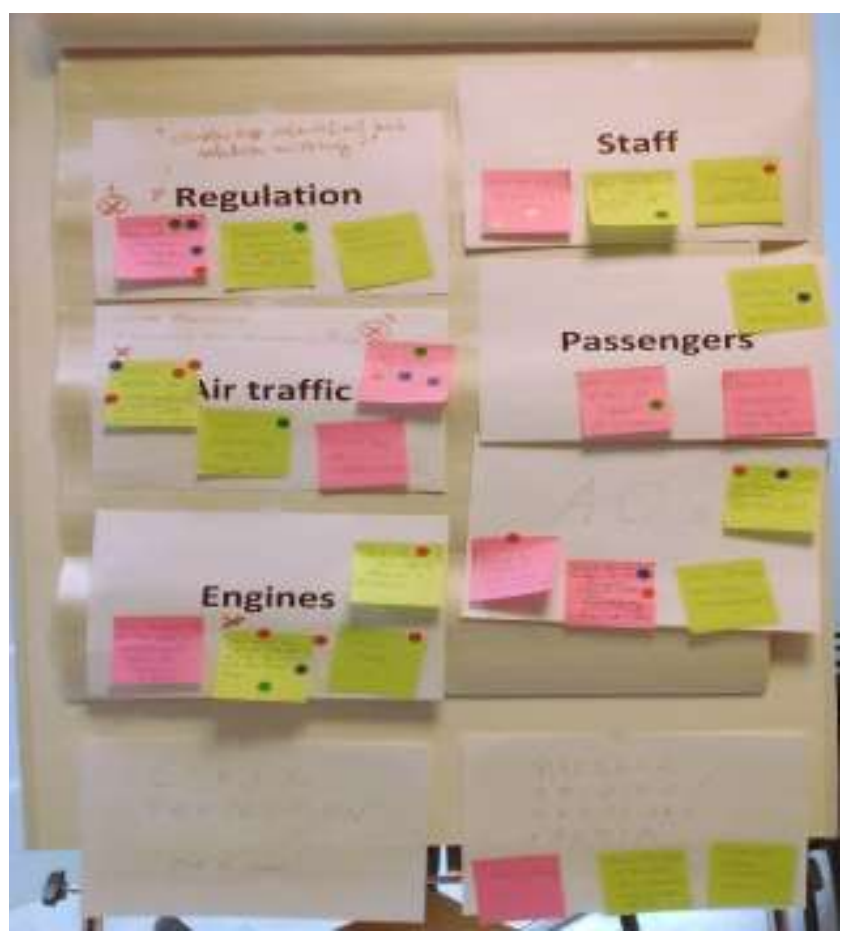

Figure 2. Stakeholder workshop: Outcome of scenario runs

(Source: Reichardt et al. 2015)

The workshop was concluded by thanking the participants for their engagement, a presentation summary of the tasks, an overview of the next steps within the project, and a feedback round with the stakeholders. They were encouraged to also provide written personal feedback.

During the course of the day the representative of Rolls-Royce offered to give a brief update presentation after the workshop about the company's undertakings with regards to volcanic ash. This was welcomed by the participants. The workshop concluded with a dinner to thank the participants and provide additional time for interaction. 


\subsection{Post-Workshop Processing}

A grouped model approach was used to capture the workshop results. The visual arrangement of the input during the workshop followed the intended outline of the result presentation to facilitate the post-workshop processing, presented in Figure 3. Obstacles in the general process, during the exploration of the extreme scenarios as well as possible solutions to these obstacles were grouped around the main focus areas. The recommendations derived from the workshop are discussed in further detail in Reichardt et al. (2018b).

Within a week after the workshop, the participants received the transcript of the meeting minutes and a two-page summary of the workshop including the agenda and results of the workshop and contact list of the attendees. They were asked to comment on the accuracy of the content and to provide suggestions for changes if needed.

\subsection{Feedback}

The stakeholder feedback was collected in two steps. A first feedback session was held at the end of the stakeholder workshop to capture the participants' impression of the workshop in detail. In a second round, feedback was collected through telephone interviews.

\subsubsection{Feedback Round within the Workshop}

The feedback round revealed that prior to the workshop, the majority of the participants had neither realized the dimensions of potential volcanic eruptions, nor the uncertainty of the impact of ash on jet engines. The workshop raised their collective awareness to these issues. One representative concluded, "After this workshop, it would be crazy to say we have done everything we can and are fully prepared. The next exercise will be a big one, for sure."

One of the main feedback issues concerned the novelty of the meeting, bringing this group together for the first time. As one participant said, "The workshop was a fantastic opportunity as this was the first time that experts from all parts of the process chain sat around one table and discussed and listened to each other." The effort spent to prepare and set up the workshop and create scenarios was appreciated. "When working in the [agency omitted], having only so many resources, you never have time to give a creative subject a full day, so this was very fruitful."

Another stakeholder highlighted the knowledge collection during the workshop: "Amazing to see your own contributions as part of the bigger picture, as a piece in a puzzle. This overview is very welcome. Through this approach, it is much easier to see the requests (from other stakeholders) vs. the potential solutions, and to try to move together toward a better response next time." The representative from ISAVIA suggested that the outcome of the workshop be presented at the next VOLCEX planning meeting. If other stakeholders at the planning meeting agree, one of the scenarios could be used for a future VOLCEX exercise. 


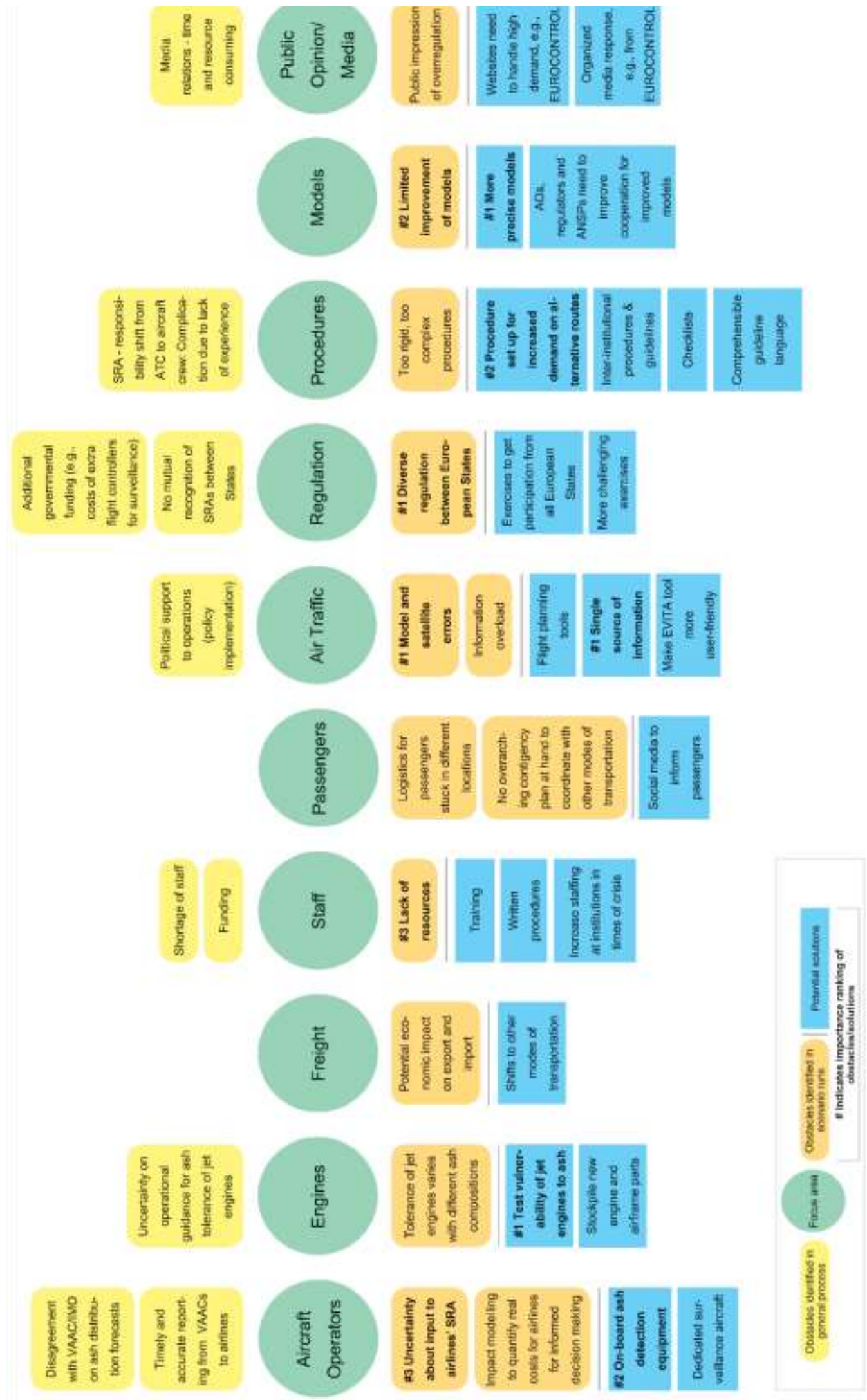

Figure 3. Workshop outcomes: Obstacles and solutions in the process (Source: Reichardt et al. 2018) 


\subsubsection{Feedback 6 months after the Workshop}

Six months after the workshop, the researchers reached out by telephone to all participants to capture feedback on their long-term impressions of the workshop and its effects. All workshop participants provided feedback with the exception of the representatives from Icelandair, where one gave feedback on behalf of the three participants. All stakeholders reiterated the uniqueness of the workshop in combining the whole chain of actors in the process, and echoed the feedback that was given directly after the workshop.

The scenario run and the discussions had affected the stakeholders' view on the situation and their work after the workshop. "It definitely has affected the way I am thinking about these issues, also during the work on the EUR/NAT contingency plan." Another representative stated, "It made me think about re-suspended ash as a particular problem in Iceland. The discussion at the workshop showed a different perspective and I digested what I learned and acted on it in the process of updating guidance."

A majority of the participants had established a contact with institutions that they were not in touch with before. In one case, this initiated collaboration between stakeholders that had not worked together before. While not everyone has made use of the new contacts since the workshop, all stated that they now know better than before whom to talk to. One participant stated, "It was very useful to meet a representative from Rolls-Royce face-to-face. We were looking for detailed information concerning the engine tolerances beforehand but could not really get hold of any, so this was very useful."

All stakeholders were interested in the outcome of the research. The feedback showed support for further cooperation and interest in taking the outcome of the workshop further. Regarding ideas for further steps, one participant summarized it as follows: "It would now need smaller groups (e.g., ISAVIA-IMO) on the national as well as on the European level to discuss. Exercises that focus on testing a specific part of a long chain (e.g., IMO, ISAVIA, Icelandair) and further help to identify obstacles and improve them would be very valuable."

Another one voiced the use of a comprehensive flow chart to illustrate "which institution is doing what and how everyone is placed in the process and what they are triggering."

Overall, the stakeholders had a positive view on the potential implementation of the measures that were developed during the workshop. However, some interviewees who were present at the workshop indicated that they were not in a position to directly implement the changes. This is an important insight and should be taken into account when planning future workshops.

The research helped identify obstacles and build a platform for the stakeholders' interaction in the future. This is captured in a participant's comment summarizing the long-term effect of the workshop: "The long-term benefits might not be visible yet but will show eventually. The workshop will become useful when entering a new ash situation. It definitely goes into the experiences and helped to be mentally prepared." 


\section{CONCLUSION}

After E2010, efforts were undertaken to increase coordination between institutions (Reichardt et al. 2017). In order to advance crisis preparedness for Icelandic volcanic eruptions, scenarios are needed that reach further in impact and intensity than E2010 to drive strategic emergency planning forward and help mitigate future impacts of volcanic eruptions (Alexander 2013).

This paper presents a multi-level approach to prepare and facilitate interaction between key stakeholders in aviation response to volcanic crises. The approach is based on solid individual preparation of the discussants followed by group discussions with the help of scenario narratives in a participatory stakeholder workshop.

The workshop set-up proved to be successful in enabling discussions and obtaining information. Its timeliness was illustrated by both the stakeholders' positive response to the invitation as well as the participants' feedback after the workshop. As the feedback showed, the meeting was appreciated as an opportunity to meet and discuss contingency issues beyond the day-to-day business. It raised awareness among the participants and enabled information flow between stakeholders. The main outcome of the workshop was threefold: First, the workshop helped facilitate discussions between stakeholders and allowed them to exchange perceptions, interests and knowledge. Secondly, it raised the stakeholders' awareness of the complexity of potential risk situations and the multitude of actors involved. Thirdly, it enhanced understanding of the risk management cycle and offered the potential to jointly identify gaps in the process.

The value of a stakeholder workshop goes beyond the collection of data. It can be important for practical reasons as well. Valuable insight may be gained through understanding why the participants chose to attend the workshop. The incentive may be to gain knowledge, contribute to improvements, or extend one's network. Making sure that these incentives can be met will help ensure the participants' attendance. In this case, the study group ensured opportunities for the participants to understand holistically the aviation sector's response to volcanic ash, make their own institution's role known, create new contacts, and enlarge their network.

A practical point is to rank participants in order of necessity for the workshop and to start with the most necessary participants when setting a date for the workshop to ensure their ability to attend. The confirmation of attendance from key stakeholders can serve as an incentive for other participants to attend.

It is important to consider the costs that participants face when attending the workshop. While institutions may be willing to contribute the hours spent on the workshop, reimbursing transportation and accommodation costs is important to guarantee attendance. The time spent at the workshop should be limited. Preliminary interviews and discussions, as well as questionnaires and necessary information handed to the participants before the workshop, increase the likelihood that the time can be used effectively at the workshop itself to obtain the required results. 
The experience from this research provides practical insight on how to successfully implement participatory stakeholder workshops, at least in the context of risk management of natural hazards. The authors have since successfully shared the experience acquired with other researchers of natural hazard risk management (NORDRESS 2016).

\section{ACKNOWLEDGEMENTS}

This work was supported in part: by the European Commission on FP7 grant number 308438, ENHANCE-Enhancing Risk Management Partnerships for Catastrophic Natural Disasters in Europe; by the University of Iceland ISAVIA Fund; and by NordForsk through the NORDRESS Centre of Excellence on Resilience and Societal Security. The authors gratefully thank the interview partners for their time and input, as well as the reviewers for their valuable input.

\section{LIST OF ABBREVIATIONS}

ADAQ - Atmospheric Dispersion and Air Quality

E2010 - Eyjafjallajökull eruption in 2010

ENHANCE - European Project on Partnerships for Disaster Risk Reduction

EU - European Union

EUR/NAT - European North Atlantic

EUROCONTROL - European Organization for the Safety of Air Navigation

FUTUREVOLC - European Project on long-term monitoring in geologically active regions

IATA - International Air Transport Association

ICAO - International Civil Aviation Organization

ICETRA - Icelandic Transport Authority

IMO - Icelandic Meteorological Office

ISAVIA - Icelandic Air Traffic Management

NAME - Numeric Atmospheric Modelling Environment, ash dispersion model

NORDRESS - Nordic Centre of Excellence on Resilience and Societal Security

TRAMS - European Project on Training and Mentoring of Science Shops

VAA - Volcanic Ash Advisories

VAA - Volcanic Ash Advisory

VAG - Volcanic Ash Graphic

VOLCEX - Volcanic Ash Exercise 


\section{REFERENCES}

Alexander, D. (2013) Volcanic ash in the atmosphere and risks for civil aviation: a study in European crisis management. International Journal of Disaster Risk Science, 4 (1): 9-19.

Compton, K., Bennett, R. A. and Hreinsdóttir, S. (2015) Climate Driven Vertical Acceleration of Icelandic Crust Measure by CGPS Geodesy. Geophysical Research Letters, 42: 743-750.

Dunn, M. G. and Wade, D. P. (1991) Influence of volcanic ash clouds on gas turbine engines. In: Volcanic Ash and Aviation Safety: Proceedings of the First International Symposium on Volcanic Ash and Aviation Safety. U.S. Geological Survey Bulletin, 2047: 107-118.

Gnaiger, A. and Schroffenegger, G. (2008) Tool-Kit Scenario Workshop, TRAMS: Training and Mentoring of Science Shops. The FBI Centre, Innsbruck, Austria. http://www.uibk.ac.at/ fbi/download/fbibuchweb1.pdf. Accessed on October 19 ${ }^{\text {th }}, 2015$.

Gudmundsson, A. T. (1987) Íslandseldar (In Icelandic. English: Iceland's Fire). Vaka Helgafell, Reykjavík.

Gudmundsson, M. T., Thordarson, T., Höskuldsson, Á., Larsen, G., Björnsson, H., Prata, F. J. and Hayward, C. L. (2012) Ash generation and distribution from the April-May 2010 eruption of Eyjafjallajökull, Iceland. Scientific reports, 2: 572.

Guffanti, M. and Miller, E. K. (2002) Reducing the Threat the Threat to Aviation from Airborne Volcanic Ash. The 55th Annual International Air Safety Seminar, 4-7 Nov., Dublin, Ireland.

Haraldsson, Ó. (2012) Gosannálar 1800-2011. Http://www.eldgos.is/gosannalar/1800-2010/. Accessed on September 4th, 2013.

Höskuldsson, A., Guđmundsson, M. T., Larsen, G. and Pórđarson, P. (2013) Eldgos. In: Júlíus Sólnes, Freysteinn Sigmundsson og Bjarni Bessason (editors): Náttúruvá á Íslandi, (In Icelandic. English: Natural Hazards in Iceland). Viðlagatrygging Íslands/Háskólaútgáfan, pp. 89-99.

ICAO (2009) Contingency Plan for Handling Traffic in the Event of Volcanic Ash Penetrating the Airspace of North Atlantic Region, Sept. 2009. European and North Atlantic Office, International Civil Aviation Organization (ICAO). http://www.skybrary.aero/bookshelf/ books/1159.pdf. Accessed on July 1 ${ }^{\text {st }}, 2015$.

IMO (2014) Catalogue of Icelandic Volcanoes. Icelandic Meteorological Institute. http://icelandicvolcanoes.is/. Accessed on November 28, 2017.

NORDRESS (2016) Herding cats...or how to successfully run a stakeholder workshop. In: Events. http://nordress.hi.is/events/herding-catsor-how-to-successfully-run-a-stakeholderworkshop/. Accessed on November 302017.

Oxford-Economics (2010) The Economic Impacts of Air Travel Restrictions Due to Volcanic Ash, Report for Airbus. Oxford http://www.oxfordeconomics.com/my-oxford/projects/129051. Accessed on August $1^{\text {st }}, 2017$. 
Pearce, F. (2012) Could a Changing Climate set off Volcanoes and Quakes? Yale Environment360, May 7, Yale University. http://e360.yale.edu/feature/could_a_changing_climate_set_off_volcanoes_and_quakes/25 25. Accessed November 18, 2014.

Petersen, G. N. (2010) A short meteorological overview of the Eyjafjallajökull eruption 14 April23 May 2010. Weather, 65 (8): 203-207.

Reichardt, U., Ulfarsson, G. F. and Pétursdóttir, G. (2015) Multi-Sector-Partnership and Disaster Resilience Schemes - Air Industry Response to Volcanic Eruptions (Europe and Iceland). In: Development of Multi-Sector Partnerships and Disaster Resilience Schemes. ENHANCE: Enhancing Risk Management Partnerships for Catastrophic Natural Disasters in Europe, Deliverable 7.4, EC Grant Agreement no. 308438.

Reichardt, U., Ulfarsson, G. F. and Petursdottir, G. (2017) Cooperation between Science and Aviation Sector Service Providers in Europe for the Risk Management of Volcanic Ash. Transportation Research Record: Journal of the Transportation Research Board, 2626, 99-105.

Reichardt, U., Ulfarsson, G. F. and Petursdottir, G. (2018a) Developing Scenarios to Explore Impacts and Weaknesses in Aviation Response Exercises for Volcanic Ash Eruptions. The 97th Annual Meeting of the Transportation Research Board. Compendium of Papers. Washington D.C., $16 \mathrm{pp}$.

Reichardt, U., Ulfarsson, G. F. and Pétursdóttir, G. (2018b) Volcanic Ash and Aviation: Recommendations to Improve Preparedness for Extreme Events. Transportation Research Part A: Policy and Practice, 113: 101-113.

Schmidt, P., Lund B., Hieronymus C., Maclennan, J., Árnadóttir, T. and Pagli, C. (2013) Effects of Present-Day Deglaciation in Iceland on Mantle Melt Production Rates. Journal of Geophysical Research-Solid Earth, 118: 3366-3379, doi:10.1002/jgrb.50273.

Ulfarsson, G. F., and Unger, E. A. (2011) A Case Study of Icelandic Aviation Impacts and Responses due to the 2010 Eyjafjallajökull Volcanic Eruption. Transportation Research Record: Journal of the Transportation Research Board, 2214: 144-151.

Wood, C. A. (1992) Climatic effects of the 1783 Laki eruption. In: Harrington, C. R. (Editor), The Year Without a Summer. World Climate in 1816. Canadian Museum of Nature, Ottawa, pp. 58-77. 